\title{
DEVELOPMENT OF METHODICAL APPROACHES TO THE CREATION OF THE PHARMACOLOGICALLY ACTIVE BANDAGE
}

\author{
KHOKHLENKOVA NV ${ }^{1 *}$, KOVALENKO SM ${ }^{2}$, AZARENKO JM ${ }^{1}$, BURYAK MV ${ }^{1}$ \\ ${ }^{1}$ Department of Drug Technology, National University of Pharmacy, Kharkov, Ukraine. ${ }^{2}$ Department of Commodity Science, National \\ University of Pharmacy, Kharkov, Ukraine. Email: hohnatal@gmail.com
}

Received: 08 April 2017, Revised and Accepted: 29 April 2017

\section{ABSTRACT}

The results of modern research on the creation of pharmacologically active bandage were generalized. The main components of the development of pharmacologically active dressing (choice of active ingredients, carrier substrate, the method of immobilization, etc.) were determined. Methodological approaches to the creation of pharmacologically active bandage were developed. The practical significance of the developed methodological approaches was demonstrated by research and development of dressings with thick oak bark extract.

Keywords: Pharmacologically active bandage, Methods of immobilization, Plaster, Medical pad, Thick oak bark extract.

(C) 2017 The Authors. Published by Innovare Academic Sciences Pvt Ltd. This is an open access article under the CC BY license (http://creativecommons. org/licenses/by/4. 0/) DOI: http://dx.doi.org/10.22159/ajpcr.2017.v10i8.19037

\section{INTRODUCTION}

Traditional medicines in the form of such dosage forms as ointments, creams, gels, pastes, liniments, tinctures, foam, powder, etc., can be used for topical application of various lesions.

Years of research in biopharmaceutics demonstrate a constant search for improving and new ways for delivery of already known medicines. With the development of scientific and technological progress and increasing pace of life, an important area of research is developing drugs for local therapy in dosage forms ensuring maximum convenience and eases of use, have high consumer quality, have directed pharmacological action. Such requirements are met by dosage forms intended for applying to the surface of the skin or mucous membranes - plasters, wipes bandages, etc.

These dosage forms are traditional while manufacturing bandaging - medical products made of one or several bandages and intended for the prevention and treatment of infected wounds, burns and other skin, tissue and mucous membranes damage [1-4].

Transdermal therapeutic systems with hormonal, cardiological, cancer, and other preparations are also produced in the form of plaster. It is a complex, efficient way to deliver drugs that require detailed study and prediction of pharmacokinetic parameters, so their development and production are quite long and have high cost [5-8].

Nowadays, the concept of pharmacologically active bandage (PhAB) includes a traditional woven and non-woven materials, dressing, film, sponge, hydrocolloids, powders, pastes, and combined materials $[2,3,9,10]$.

According to modern requirements of medicine and pharmacy, the wound closure materials market is developing rapidly. Besides traditional wound closure materials, the range of innovative bandages and wound closure is gradually expanding, including biologically active materials based on alginic acid, which, while contacting with exudate, turns into gel, osmotically active bandages that remove necrotic tissues from a wound, adsorbing bandages with activated carbon that can remove foul smell, and other innovative products. However, according to the studies, currently, their range is not wide enough.
The range of wound closure materials in Ukraine is represented by gossypium (11.67\%), gauze fabric (10.34\%), drapes (5.84\%), various bandages $(19.09 \%)$ and plasters $(36.88 \%)$, compresses $(1.33 \%)$, bandaging packs (1.59\%), and bands (13.26\%) [11]

The functions of wound closure materials are protection from the external environment (traumatic factors, excessive moisture or drying, dust, dirt, desquamated epithelium), prevention of wound contamination by microorganisms, removal of tissue decay products, microorganisms, toxins, enzymes, therapeutic effect (antimicrobial, hemostatic, analgesic, regenerating, immunostimulatory, etc.), and fixation of drug on a wound [12-14].

According to this, turner has formulated the criteria for the socalled "ideal bandaging:" (1) removing exudate; (2) creating moist environment; (3) ability for gas exchange; (4) maintaining temperature control; (5) preventing infection; (6) non-toxic; (7) noninvasiveness $[3,14-16]$.

With the development of science and technology, there appeared such additional requirements as active effect on wound process by introducing medicinal agent, possibility of contactless visual control over the wound, resistance to sterilization, ease of use, duration of use on wounds, etc. $[3,15]$.

The task of bandaging varies in each phase of wound healing. In the inflammation phase, there can be used both wet and dry bandages that are designed to remove excess exudate with bacteria, toxins, detritus, debrides, and keep them with the structure of a bandage; stimulate rehydration and accelerate necrolysis; protect against recontamination $[10,14,17]$. In the granulation phase, non-invasive hydroactive bandages are preferred that maintain moist environment (absorb excess secret, prevent drying of the wound and if necessary provide it with measured dosage of moisture); condition wounds; protect from mechanical damage and secondary infection. The task of the epithelialization phase is maintaining moist environment; protecting epithelium and open sword cut from mechanical damage during bandaging; stimulating regeneration $[10,13]$.

The aim of this article is to identify the main components of the development process of pharmacologically active bandage (PhAB) and develop a methodological approach to create them. 
The vast majority of pharmacologically active patches and dressings on the Ukrainian market refer to medical products; therefore, the development and production of $\mathrm{PhAB}$ need to meet the requirements of the corresponding standard documentation.

In Ukraine, Technical Regulations on Medical Products (Decree dated: 11.06.2008 №. 256) have been valid since 2008, that define general requirements to a product (including bandage), its safety and conformity procedures. According to the Ukrainian legislation, transdermal plasters, and $\mathrm{PhAB}$ belong to drugs and must meet the general requirements for drugs.

In the development and implementation of PhAB for high-quality products certain requirements must be met $[1,3,15,18]$ to:

- The choice of materials, in particular regarding their toxicity and safety;

- The compatibility of the materials with the tissues, cells, and body fluids of the human body taking into account the purpose of the product;

- Effect on human tissue, duration, and frequency of the application;

- Elimination or maximum reduction of the risk of a patient, user, or another person;

- Packing of non-sterile and sterile medical products.

PhAB may have a local effect on the surface of the skin or mucous membranes, and the overall effect on the body as a whole.

To develop, PhAB for local application depending on the goal of research, anti-inflammatory, antibacterial, antifungal, local anesthetic, antihistamines, and some other media can be selected as the active substance.

$\mathrm{PhAB}$ can be made in two ways - without using media and by applying composition of some active substance (as a solution, emulsion, suspension, gel, etc.) to a specific media (woven or non-woven material, film, etc.).

$\mathrm{PhAB}$ made without media are represented by synthetic (polylactide, polyvinyl, etc.) and polysaccharide coatings, such as a water-soluble derivative of cellulose, chitosan, calcium, and/or sodium alginate, made in the form of hydrophilic fibrous nonwoven material; alginate, collagen and chitinous sponges, films, and membranes [19-22].

The following application materials are biodegradable and completely dissipate on a wound. However, the appropriateness of their use in the treatment of wound healing process is a matter of scientific discussions, since the products of degradation of such bandage remain in the wound without being removed [23-26].

The second method involves the immobilization of active substance on a specific media and is based on physical (electrostatic, dispersion, and hydrophobic) and/or chemical interactions of biologically active substances with the media. The immobilization methods can be divided into physical, chemical, and combined. The choice of method of immobilization largely depends on physical-chemical properties of the active substance $[1,3]$

The simplest methods of physical immobilization of drugs on the media are adsorption from the saturated composition by dipping material in solution and applying saturated composition in the form of gel, powder, and paste on the surface of the media. These methods are the easiest in implementation and economically most beneficial, but their disadvantage is quite weak retention of the components of saturated composition on the media surface $[1,2,27]$.

A kind of physical immobilization is the printing method, which involves the introducing biologically active substances in saturated polymer composition (e.g., based on polysaccharides), and applying it on textile material.
For applying the composition, traditional technologies can be used that are employed while processing of fabrics - printed through a mesh pattern. This method of PhAB production ensures their long pharmacological effect in operational process and makes it possible to achieve sufficiently high concentrations of drugs on media. Virtually all drugs can be introduced into a polymer composition, including those insoluble in the components of a composition. The disadvantage of this method is the complexity of the process hardware $[1,2,3,15]$.

The chemical immobilization methods include joining biologically active substance to the media with a chemical bond. This method is the most time-consuming, technically complicated method of immobilization. Mass transfer of the drug from the textile material into the environment is conducted providing further hydrolytic degradation of linking between functional groups of partners, involved in the reaction. Active substance has to be specially prepared (chemically modified), and its linking with the media must be both robust enough and labile. The formation of different types of chemical bonds when creating immobilized agents depends, on the one hand, on the reactive capable fiber groups and, on the other hand, on the presence of such groups in preparation.

Due to the complexity and high cost, the chemical immobilization methods have not been properly developed yet. They may be justified in case of effective, unique drugs used in low concentrations, e.g., for the immobilization of enzymes.

Immobilization on the media could also be achieved by combining physical and chemical methods, such as including biologically active substances into the solution for making fiber for further manufacturing of textile material with specific therapeutic properties $[27,28]$.

One of the parameters that affect the quality of PhAB is the choice of media. The choice is made among the materials permitted for application in medicine, taking into account medical, biological, and technological requirements to the material. The media must be resistant to chemical and microbial biodegrade have high mechanical resistance, possess minimum non-specific adsorption, be able to conjugate with active components and not inhibit the action of the active substance, should not cause mechanical or chemical irritation or have cytotoxic and sensitization influence $[1,2,27]$.

Depending on the purpose and place of applying the product, there are different requirements for mechanical properties of material. Providing it is applied to a wound, ulcer, or burnt surface, untraumatic thin material is preferred.

When used on the surface of the body that involves frequent bandage deformation (e.g., limbs, elbow joints), an important aspect of choosing material is studying its bursting properties when wet [12-15]. Depending on the type and structure of material, the bursting stress value varies significantly.

An important requirement to the media of bandage is possibility of oxygen and carbon dioxide exchange and humidity regulating. Permeability for gasses and moisture depends on the structure and nature of the material and is listed by the manufacturer in the legal requirements for the product. Textiles, such as gauze, nonwoven material, have higher permeability than products of synthetic materials (e.g., hydrogel or hydrocolloid bandages with their occlusal properties) $[1-3,15,27]$

In developing bandaging for treating inflammatory lesions at the stage of selecting media, hygroscopic characteristics of the material - capillarity, wetting speed - should be considered.

Capillarity criterion is the ability of material to absorb effectively exudate and purulent discharge and drain the wound and is determined by the height of colored liquid lifting (e.g., a solution of potassium dichromate $\mathrm{R}$ ) along a vertically fixed sample material for 1 hour. 
Capillarity index of $<100 \mathrm{~mm} / \mathrm{h}$ characterizes low capacity of a bandage to clean the wound [1-3].

The modern materials used as media for bandaging may be of natural or synthetic origin, be inert or possess its activity.

Among natural organic media cellulose as gauze and other materials (methylcellulose, carboxymethylcellulose, bromoacetylcellulose, microcrystalline cellulose, etc.), textiles, collagen, starch, dextrin (sephadex), agar (sepharose), glycogen, and chitin and their derivatives, whose activity is caused by a chain structure of macromolecules and ability of hydrophilic functional groups to bind tightly molecules of water environment and organic components of exudate and form a spatial cross-linking (grids) are used.

Synthetic organic media are represented by acrylate polymers (acrylamide), ion exchange resins, nylon, polyvinyl alcohol, polyurethane, polyoxyether, organometallic polymers, etc.

Materials based on natural compounds are usually well compatible with body tissues. In contrast, synthetic polymers contain a number of chemically reactive monomers and products of their reactions and polymerization catalysts, which increases the risk of local irritant action [1-3,29-32].

The range of media for producing bandaging widens at the expense of polymers that have smooth surface, are easy and noninvasively removed, and do not slow down regenerative processes. Some polymer films already contain antiseptic and hemostatic drugs. Polymeric perforated film, film bandage with polyvinyl chloride, etc., are produced. All these materials have the advantage - noninvasiveness but have worse drainage properties compared to cotton-gauze and non-woven material.

To ensure a therapeutic effect of pharmacologically active bandaging, one of the most important aspects is explaining the choice of auxiliary substances (solvents, polymers, etc.)

To the solvents used to prepare saturated solutions, the following requirements are set $[1,3,32]$ :

- Storage stability;

- Instant sufficient capacity;

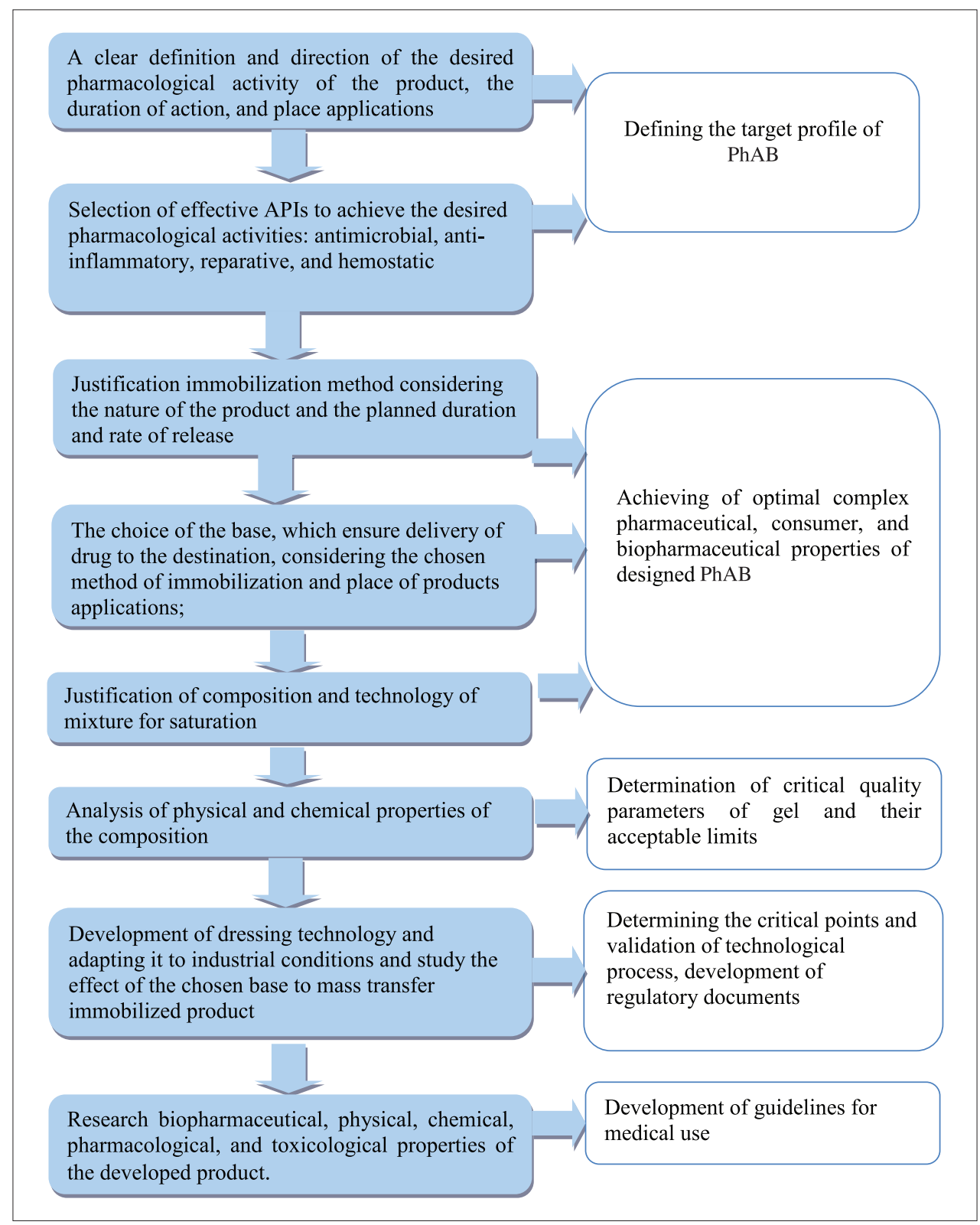

Fig. 1: Methodological approaches of development of the PhAB 
- Economic accessibility;

- Thermal stability;

- Biological compatibility;

- Minimal risk of side effects

When choosing a solvent, the possibility of interaction with other components of the solution and the impact on the adsorption processes that can significantly affect bioavailability must be considered

Providing a medicinal product is applied as a part of polymer composition, choosing the polymer, which directly affects the speed and completeness of drug release is an important step of the research.

For this purpose, synthetic and natural substances - polyvinyl alcohol, alginates, collagen, chitosan, cellulose, gelatin, etc., - are used $[15,17,21,33-36]$.

To justify, the choice and concentration of the polymer when creating saturated solutions, it is advisable to study the rheological parameters of the compositions (thixotropy, viscosity, etc.). For each polymer substance, there should be experimentally set the optimal concentration that will provide strength and structuring of the composition necessary for the process. The viscosity required for the saturating solution depends on the method of application and equipment, which is used and is determined experimentally.

One of the main factors that can significantly influence therapeutic effect of bandaging is the concentration of active ingredients in it. Biopharmaceutical studies show that for every substance of the optimum concentration may be determined beyond which its increase will not lead to a significant increase in its pharmacological activity. The optimum concentration of drug in the product should be clearly justified basing on pharmacological or microbiological research.

To prevent, the growth of microbial contamination during storage or use, medicinal products must have an effective preservative effect. Microbiological purity of drugs is provided either by introducing antimicrobial preservatives or due to preserving antimicrobial activity of active substances and appropriate conditions of production.

Bandaging does not have such stringent requirements, but in the case of a large wound surface, further contamination of the wound is not very desirable.

The research of biopharmaceutical, pharmacological, and toxicological characteristics of the developed bandaging is the final stage of research and allows to evaluate therapeutic and consumer product quality.

\section{RESULTS AND DISCUSSION}

Based on the foregoing, we have formulated methodological approaches to creating $\mathrm{PhAB}$ in the process of development, which are the following stages (Fig. 1)

We have used this approach in the development of PhAB based on thick oak bark extract - plaster and napkins $[37,38]$.

An integrated approach to developing new PhAB using modern scientific methods allows getting highly efficient products that meet the requirements of medicine and pharmacy in the rapid development of science and technology.

\section{CONCLUSIONS}

1. The results of current research on developing pharmacologically active bandaging are generalized.

2. The main components of the process of developing pharmacologically active bandaging (choice of active substances, media, the method of immobilization, etc.) are defined.

3. Methodological approaches to developing pharmacologically active bandaging using modern scientific methods of research are developed.

\section{REFERENCES}

1. Legeza VI, Remizov DV, Rumor SI. Therapeutic properties of modern dressings (review of literature). Medico biol Socio Psychol Probl Saf Emerg 2010;2:31-9.

2. Shapovalov SG. Modern wound coverings in combustiology. News Sci Technol 2007;1:182-2

3. Yudanova TN, Reshetov IV. Modern wound coatings: Production and properties (review). Chem Pharm J 2006;40(2):24-31.

4. Hersh AL, Chambers HF, Maselli JH, Gonzales R. National trends in ambulatory visits and antibiotic prescribing for skin and soft-tissue infections. Arch Intern Med 2008;168(14):1585-91.

5. Dhawan S. High molecular weight polyethylene oxide - Based drug delivery systems. Part 1: Hydrogels and hydrophilic matrix systems. Pharm Technol 2005;29(5):72-80.

6. Pielesz A, Paluch J. Therapeutically active dressings - Biomaterials in a study of collagen glycation. Polim Med 2012;42(2):115-20.

7. Kim JO, Choi JY, Park JK, Kim JH, Jin SG, Chang SW, et al. Development of clindamycin-loaded wound dressing with polyvinyl alcohol and sodium alginate. Biol Pharm Bull 2008;31(12):2277-82.

8. Gupta SS, Singh O, Bhagel PS, Moses S, Shukla S, Mathur RK. Honey dressing versus silver sulfadiazene dressing for wound healing in burn patients: A retrospective study. J Cutan Aesthet Surg 2011;4(3):183-7.

9. Leaper D, McBain AJ, Kramer A, Assadian O, Sanchez JL, Lumio J, et al. Healthcare associated infection: Novel strategies and antimicrobial implants to prevent surgical site infection. Ann R Coll Surg Engl 2010;92(6):453-8.

10. Robson MC, Steed DL, Franz MG. Wound healing: Biologic features and approaches to maximize healing trajectories. Curr Probl Surg 2001;38(2):72-140.

11. Khokhlenkova NV, Yarnyh TG, Kupriyanova OM. Studying the range of dressing in Ukrainian pharmaceutical market. Pharm J 2009;4(9):61-3.

12. Vermeulen H, Ubbink D, Goossens A, de Vos R, Legemate D. Dressings and topical agents for surgical wounds healing by secondary intention. Cochrane Database Syst Rev 2004;2:CD003554.

13. Rathinamoorthy $\mathrm{R}$, Sasikala L. Polysaccharide fibres in wound management. Int J Pharm Pharm Sci 2011;3(3):38-44.

14. Greenhalgh D. Models of wound healing. J Burn Care Rehabil 2005;26(4):293-305.

15. Green B. Making an informed decision: How to choose the correct wound dressing. Wound Heal South Afr 2013;6(1):12-20.

16. Han JY, Choi-Kwon S. Adaptation of evidence-based surgical wound care algorithm. J Korean Acad Nurs 2011;41(6):768-79.

17. Ather SH, Chan D, Harding K. The biology of wound healing. Wound Manage 2007;13(13):53-4

18. Bhattacharya S, Tripathi HN, Gupta V, Nigam B, Khanna A. Collagen sheet dressings for cutaneous lesions of toxic epidermal necrolysis. Indian J Plast Surg 2011;44(3):474-7.

19. Hill KE, Malic S, McKee R, Rennison T, Harding KG, Williams DW, et al. An in vitro model of chronic wound biofilms to test wound dressings and assess antimicrobial susceptibilities. J Antimicrob Chemother 2010;65(6):1195-206

20. Liakos I, Rizzello L, Bayer IS, Pompa PP, Cingolani R, Athanassiou A. Controlled antiseptic release by alginate polymer films and beads. Carbohydr Polym 2013;92(1):176-83.

21. Murakami K, Aoki H, Nakamura S, Nakamura S, Takikawa M, Hanzawa $\mathrm{M}$, et al. Hydrogel blends of chitin/chitosan, fucoidan and alginate as healing-impaired wound dressings. Biomaterials 2010;31(1):83-90.

22. Hall KK, Gattás-Asfura KM, Stabler CL. Microencapsulation of islets within alginate/poly(ethylene glycol) gels cross-linked via Staudinger ligation. Acta Biomater 2011;7(2):614-24.

23. Bi Q, Zhang Q, Ma J, Xu M, Zhang SJ, Qiu BS, et al. Effect of combination therapy with alginate dressing and mouse epidermal growth factor on epidermal stem cells in patients with refractory wounds. Chin Med J (Engl) 2012;125(2):257-61.

24. Peppas NA, Bures P, Leobandung W, Ichikawa H. Hydrogels in pharmaceutical formulations. Eur J Pharm Biopharm 2000;50(1):27-46.

25. Thomas JG, Slone W, Linton S, Okel T, Corum L, Percival SL. In vitro antimicrobial efficacy of a silver alginate dressing on burn wound isolates. J Wound Care 2011;20(3):124, 126-8.

26. Goh $\mathrm{CH}$, Heng PW, Huang EP, Li BK, Chan LW. Interactions of antimicrobial compounds with cross-linking agents of alginate dressings. J Antimicrob Chemother 2008;62(1):105-8. 
27. Oltarzhevskaya ND, Korovin MA. Textiles for medicine: New therapeutic composite materials. Text Ind 2010;5:58-62.

28. Buzov BA, Makarova NA, Mishakov VY. The main indicators of the quality of textile antimicrobial materials for medical purposes.Tech Text 2003;8:10-8

29. Pielesz A, Katarzyna B, Klimczak M. Physico-chemical properties of commercial active alginate dressings. Polim Med 2008;38(4):3-17.

30. Tuncer C, Demirci S, Eroglu M. Poly(ethylene oxide) and its blends with sodium alginate. Polymer 2005;46:10750-7.

31. Pongjanyakul T, Puttipipatkhachorn S. Sodium alginate-magnesium aluminum silicate composite gels: Characterization of flow behavior, microviscosity, and drug diffusivity. AAPS PharmSciTech 2007;8(3):E72.

32. Kalász H, Antal I. Drug excipients. Curr Med Chem 2006;13(21):2535-63

33. Beele H, Meuleneire F, Nahuys M, Percival SL. A prospective randomised open label study to evaluate the potential of a new silver alginate/carboxymethylcellulose antimicrobial wound dressing to promote wound healing. Int Wound J 2010;7(4):262-70.

34. Chiu CT, Lee JS, Chu CS, Chang YP, Wang YJ. Development of two alginate-based wound dressings. J Mater Sci Mater Med 2008;19(6):2503-13.

35. Zevedo EP. Chitosan hydrogels for drug delivery and tissue engineering applications. Int J Pharm Pharm Sci 2015;1:8-14.

36. Priyaah K, Arun G, Swati S. Synthesis of wound-healing keratin hydrogels using chicken feathers proteins and its properties. Int J Pharm Pharm Sci 2017;1:171-8

37. Khokhlenkova NV, Kupriyanova OM. Development of Healing Antiseptic Wipes with a Thick Oak Bark Extract and Sodium Alginate. Proceedings of Staff NMAPE; 2011. p. 565-9.

38. Khokhlenkova NV, Yarnyh TG, Kupriyanova OM. Development of antiseptic hemostatic patch wth thick oak bark extract. J Pharm 2012;2(70):14-6 